LA-7426-MS

Informal Report
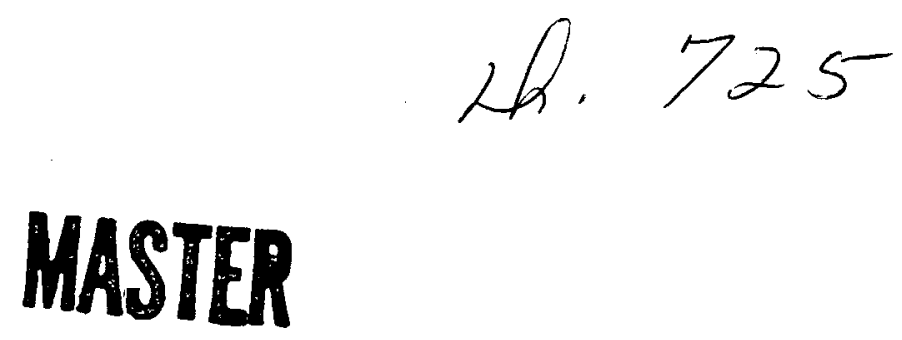

\title{
A Magnetic Induction Technique for Mapping Vertical Conductive Fractures: Electronic Design
}




\section{DISCLAIMER}

This report was prepared as an account of work sponsored by an agency of the United States Government. Neither the United States Government nor any agency Thereof, nor any of their employees, makes any warranty, express or implied, or assumes any legal liability or responsibility for the accuracy, completeness, or usefulness of any information, apparatus, product, or process disclosed, or represents that its use would not infringe privately owned rights. Reference herein to any specific commercial product, process, or service by trade name, trademark, manufacturer, or otherwise does not necessarily constitute or imply its endorsement, recommendation, or favoring by the United States Government or any agency thereof. The views and opinions of authors expressed herein do not necessarily state or reflect those of the United States Government or any agency thereof. 


\section{DISCLAIMER}

Portions of this document may be illegible in electronic image products. Images are produced from the best available original document. 
An Affirmative Action/Equal Opportunity Employer

This report was prepared as an account of work sponsored by the United States Government. Neither the United States nox the United States Department of Energy, nor any of their employees, nor any of their contractors, subcontractors, or their employees, makes any warranty, express or implied, or assumpleness or usefulness of any information apparas. completeness. or usefulness of any information, apparatus, not infringe privately owned rights.

UNITED STATES DEPARTMENT OF ENERGY DEPARTMENT OF ENERGY
CONTRACT W-7405-ENG. 36 
LA-7426-MS

Informal Report

UC-66b

Issued: September 1978

\title{
A Magnetic Induction Technique for Mapping Vertical Conductive Fractures: Electronic Design
}

\author{
J. A. Landt \\ A. R. Koelle \\ M. A. Trump \\ J. D. Nickell, Jr.
}
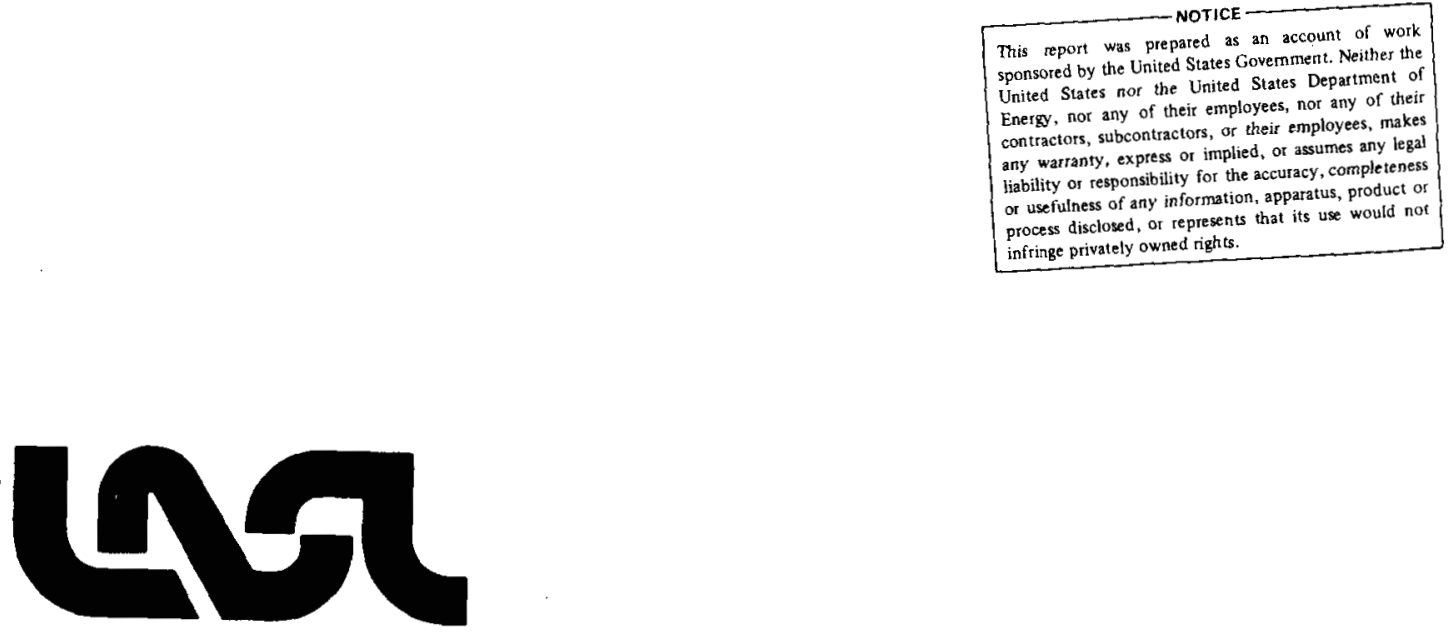


\section{A MAGNETIC INDUCTION TECHNIQUE FOR MAPPING \\ VERTICAL CONDUCTIVE FRACTURES: ELECTRONIC DESIGN}

by

J. A. Landt, A. R. Koel1e, M. A. Trump, and J. D. Nickell, Jr.

ABSTRACT

This report is the last in a series that describes the preliminary design of an instrument capable of mappino conductive fractures deep below the surface of the earth. Earlier reports dealt with thecretical analysis, the general status of the instrument development, and materials vendor searches. Here, attention is focused on the electronics desian and prototype hardware to perform the mapping task. A phase-sensitive detector is described that has a sensitivity in the tens of nanovolts. Coil-switching circuitry is also described, as well as a downhole data ink tailor-made for this particular instrument's needs.

\section{INTRODUCTION}

The orientation and location of vertical hydraulic fractures is of vital concern in the production of geothermal energy from hot dry rock. ${ }^{1}$ Consequently, the LoS Alamos Scientific Laboratory (LASL) has been keenly interested in fracture mapping techniques in support of their geothermal hot. dry rock demonstration project. Many fracture mapping techniques have been considered and attempted, as summarized in "Status Report of the Vertical Conductive Fracture Detector." 2 The basis for the operation of this technique is the same as that used in the commercial induction logging instruments. ${ }^{3,4}$ A theoretical treatment of this new magnetic induction technique is provided in "A Magnetic Induction Technique for Mapping Vertical Conductive Fractures: Theory of Operation." 5

\section{OPERATIONAL REQUIREMENTS}

The vertical conductive fracture detector senses eddy currents induced in the fracture by a transmitting coil contained in the instrument, much like the operation of commercial induction loggers.
The eddy currents can be detected by measuring their magnetic field with a receiving coil. The received signal (voltage in the receiving coil) is given by

$V_{r}=\operatorname{CI\sigma t} \cos ^{2} B$,

where $C$ is a constant depending on coil design, electrical frequency, etc., $\sigma$ is the electrical conductivity, and $t$ is the thickness of the fracture. $B$ is the angle between the plane of the fracture and the plane of the coils, and $I$ is the current in the transmitter coil. The present coil designs and expected fractures will produce a received voltage of $0.2 \times 10^{-6} \mathrm{~V}$ with a drive current of $100 \mathrm{kHz}$ and $10 \mathrm{~mA}$.

The fracture orientation is found by rotating the coils and finding the angle $\beta$ for which the signal is maximum. This mapping involves several elements:

(1) Determine the orientation of the instrument case as a reference, provided by the earth's natural magnetic field. 
(2) Rotate the coils to determine the greatest received signal. This rotation can be accomplished electronically, involving no mechanical motion, if two identical coil sets oriented at right angles to each other are used.

The environmental operating requirements are $275^{\circ} \mathrm{C}$ and $7 \times 10^{7} \mathrm{~Pa}(10000$ psi). At the present state of the art, these requirements dictate the use of a thermally protected pressure housing for the electronics.

The coils must be located in a nonconductive housing, and the borehole fluid must be displaced in the vicinity of the coils. These requirements lead to major mechanical complexities, which have been addressed in a separate report. 5

\section{CONCEPTUAL DESIGN}

A block diagram of the instrument is shown in Fig. ]. A separate report ${ }^{6}$ covers materials considerations, hydraulic system design, and conceptual mechanical design. Here, emphasis will be given to the electronic subsystems.

A typical measurement scenario is:

(1) Position instrument at desired depth.

(2) Inflate bladder by supplying power to "inflate" wire pair.

(3) When motor current indicates stall (b)adder expanded), disconnect power to inflate wire pair.

(4) Turn experiment "on" by supplying $150 \mathrm{Vac}$, $60 \mathrm{~Hz}$ to experiment power wire pair. The experiment will automatically sequence through a set measurement procedure. Magnetic north, as well as several outputs proportional to fracture eddy currents, will be measured and sent to the surface.

(5) When desired, turn "off" experiment by removing the power to the experiment power wire pair.

(6) Deflate bladder by supplying power to "deflate" wire pair.

(7) When motor current indicates stall, remove power from deflate wire pair. Instrument may then be repositioned at another depth.

To conserve energy and extend downhole operating time, power to each subsystem will be turned off if that subsystem is not being used.

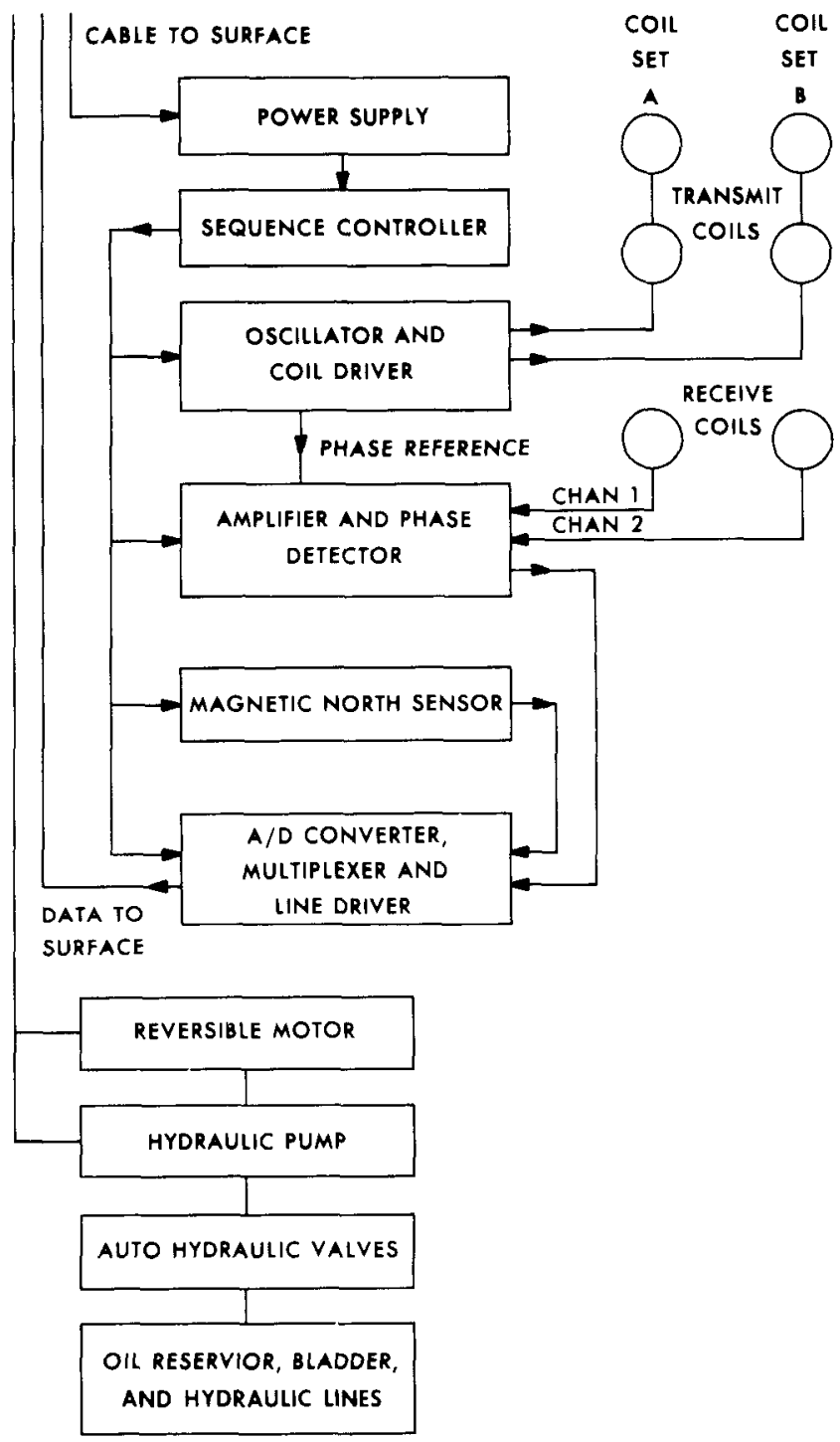

Fig. 1. Vertical conductive fracture detector.

The experiment [item (4) above] consists of several parts, each controlled by the sequence controller that starts automatically when it receives power.

(a) Measure magnetic north direction.

(b) Transmit in coil set $A$ and receive in channe 11.

(c) Transmit in coil set $A$ and receive in channel 2.

(d) Transmit in coil set $B$ and receive in channel $?$.

(e) Transmit in coil set $B$ and receive in channel 2. 
(f) Receive in channels 1 and 2 with no coils transmitting.

(g) Reverse polarities on several of the items $b$ through $e$ and repeat the measurements.

Measurements $b$ through e permit a "synthesized" coil rotation to be performed mathematically, which yields the desired angle $\beta$ of the fracture. Measurements $f$ and $g$ provide data on electronics performance and allow some measurement errors to be corrected.

\section{SPECIFICATIONS}

The specifications and general considerations of the electronic subsystems are

A. Power Supply

PURPOSE : To provide dc power for the experiment.

SUPPLIER: Semiconductor Circuits, Inc., 306

River St., Haverhi11, MA 01830, or equivalent.

INPUT : $150 \mathrm{~V}, 60 \mathrm{~Hz}$ from surface.

OUTPUT : $\pm 6 \mathrm{Vdc}, \pm 12 \mathrm{Vdc} m A$ total output.

SIZE : Must fit within a $7.1-\mathrm{cm}-(2.8-i n .-)$ diam tube.

OPERATING REQUIREMENTS: Must provide well-regulated and filtered dc outputs; will consume as little internal power as possible. All electronic equipment is to be powered from this

device so that grounding and shielding requirements of the other subsystems must be considered. The experiment will be turned on by applying the $150 \mathrm{Vac}$ from the surface to the power supply, which in turn provides power to the signal processor and sequencer.

\section{B. Sequence Controller}

PURPOSE : To sequence through the experiment, each new state being set automatically upon command from the signal processor.

SUPPLIER: LASL design.

INPUT : $\pm 6 \mathrm{Vdc}, \pm 12 \mathrm{Vdc},+6 \mathrm{~V}$ pulse from signal processor.

OUTPUT : Appropriate voltages and currents to set the necessary relays, switches, and equipment to the proper state. Also send the processor an indication of the state that was set.

SIZE : Must fit in a $7.1-\mathrm{cm}-(2.8-\mathrm{in.-})$ diam tube.
OPERATING REQUIREMENTS: Must reset when power is turned on, then step through experiment when commanded by the processor. The sequence of the experiment will be determined before detailed design of the sequencer. Time between states will be $4 \mathrm{~s}$. At least four devices will be controlled.

c. Oscillator and Coil Drivers

PURPOSE : To provide a stable, well-controlled drive coil current.

SUPPLIER: LASL design.

INPUT : $\pm 6 \mathrm{VdC}$ and $\pm 12 \mathrm{Vdc}$, controls from sequencer.

OUTPUT : $\sim 10 \mathrm{~mA}, 100 \mathrm{kHz}$, feeding a series resonant coil of several $\mathrm{mH}$ inductance. Also a reference voltage in phase with the drive current.

SIZE : Must fit in a $7.1-\mathrm{cm}-(2.8-$ in.-) diam tube.

OPERATING REQUIRMENTS: Specifications on stability of amplitude and frequency to be set later, but most likely within several per cent. Either of two coils will be driven with either polarity upon command from the sequencer.

D. Amplifier Phase-Sensitive Detector

PURPOSE : To provide a dc output proportional to the received signal in phase with the transmitting coil current.

SUPPLIER: LASL design.

INPUT : $\pm 6 \mathrm{Vdc}, \pm 12 \mathrm{Vdc}$, twisted pair from receiver coil of signal approximately $0.2 \mu \mathrm{V}$. OUTPUT : -6 to $+6 \mathrm{Vdc}$ corresponding to received signal in phase with the transmitter coil current.

SIZE : Must fit in a $7.1-\mathrm{cm}-(2.8-\mathrm{in.-})$ diam tube.

OPERATING REQUIREMENTS: The desired signal will be in the range of 0.01 to $1 \mathrm{HV}$ in the total signal of possibly several microvolts. Phase errors will be set later upon analysis of the experiment, but should be less than $2-3^{\circ}$.

Readings will be taken at least once every $4 \mathrm{~s}$. Input power and switching will be controlled by the sequencer. Two channels of different gain may be used to cover a larger dynamic range than would be available with one channe 1 . 
E. Coil Sets

PURPOSE : To induce eddy currents in the conductive fracture and measure the resulting magnetic field.

SUPPLIER: LASL design.

INPUT : $10 \mathrm{~mA}, 100 \mathrm{kHz}$.

OUTPUT : Signal from fracture.

SIZE : Must fit within bladder and dielectric housing, overall o.d. is $15.2 \mathrm{~cm}$ ( $6 \mathrm{in.}$ ).

Maximum length of dielectric space is $1.5 \mathrm{~m}$ $(\sim 5 \mathrm{ft})$.

OPERATING REQUIREMENTS: To provide a signal proportional to the eddy currents in the fracture. Appropriate grounding, shielding, and bucking will be determined. Two sets of coils with perpendicular magnetic moments are required. These two sets should be identical.

F. Magnet ic North Sensor

PURPOSE : To find magnetic north.

SUPPLIER: Various off-the-shelf items are under consideration.

INPUT : 14-34 Vdc at $35 \mathrm{~mA}$.

OUTPUT : One or two channels, 0 to $+5 \mathrm{Vdc}$, $+2.5 \mathrm{Vdc}$ nominal, $0-500 \mathrm{~Hz}$ response.

SIZE : $3.1 \mathrm{~cm}(1-1 / 4$ in. $)$ by $3.5 \mathrm{~cm}(1-3 / 8$ in.) by $10.1 \mathrm{~cm}(4 \mathrm{in.}$ ). The Schoenstedt device requires gimbals and will fit in a $6.4-\mathrm{cm}-$ (2-1/2 in.) diam tube. The Humphrey device has a built-in gimbal but requires housing modification.

OPERATING REQUIREMENTS: Other equipment should be turned off. No dc currents near the device; dc motors may require magnetic shielding. Dewar and pressure housing must be nonmagnetic. Present devices are self-contained but need thermal protection.

G. A/D Converter, Multiplexer, and Line

Driver

PURPOSE : To receive and digitize analog data and send it uphole for recording and data analysis.

SUPPLIER: LASL Design.

INPUT : $\pm 6 \mathrm{Vdc}, \pm 12 \mathrm{Vdc}, 2 \mathrm{~W}, 16$ data channels, -6 to $+6 \mathrm{Vdc}$.

OUTPUT : Analog signals digitized to 12 bits and sent uphole at a rate of 4 measurements/s.

Four seconds required for complete sequence.
Sequence automatic. Flag provided for sequencer to indicate end of data sent.

SIZE : About $25.4 \mathrm{~cm}\left(10 \mathrm{in.}{ }^{3}\right)$ to fit in a 7.7-cm- (2.8-in.-) diam tube.

OPERATING REQUIREMENTS: Temperature held to $85^{\circ} \mathrm{C}$ maximum. Must drive $15000 \mathrm{ft}$ of cable. Cable is seven random insulated strands inside a stee 1 jacket. Strand resistance, $\sim 10 \Omega / 1000$ $\mathrm{ft}$. Interstrand insulation, $10 \mathrm{k} \Omega$.

\section{v. ELECTRONIC DESIGN}

Electronic design and breadboarding have been completed on all of the electronic items listed previous $7 y$, with the exception of the sequence controller. Consideration was given to the size and power requirements of each subsystem, but no ruggedized construction was started because the mechanical design was not yet complete. The results of these design efforts are given here.

\section{A. Power Supply}

An adequate commercial power supply module is the Model P2.12.200M from Semiconductor

Circuits, Inc. It measures $6.4 \mathrm{~cm}(2.5 \mathrm{in.})$ by 3.2 $\mathrm{cm}(1.25 \mathrm{in})$ by $8.9 \mathrm{~cm}(3.5 \mathrm{in.})$, and will supply 12 Vdc. Output regulation is $\pm 0.01 \%$, with a line voltage variation from $105-125 \mathrm{Vac}$ at $50-400 \mathrm{~Hz}$, at a current of $200 \mathrm{~mA}$. The $\pm 6 \mathrm{Vdc}$ will be derived from the \pm 12 Vdc with a simple transistor regulator. B. Sequence Controller

Detailed electronic design of this item will be postponed untir the mechanical design has begun. c. Oscillator and Coil Drivers

Two main parts to the circuitry for measuring eddy current signals are (1) the $100-\mathrm{kHz}$ coil

drivers and associated $100-\mathrm{kHz}$ generator and drive controls, and (2) the 2-channel input high-gain $100-\mathrm{kHz}$ receiver amplifier, which includes a phasesensitive detector and postdetector low-pass filter and amplifier. The two circuit blocks are connected together, in addition to the eddy current coupling to be detected, by the $100-\mathrm{kHz}$ reference phase signal generated in the driver section and used in the phase-sensitive detector.

The $100-\mathrm{kHz}$ working frequency is generated in an XR2206 integrated circuit shown in Fig. 2. This device is basically an RC oscillator, in which the timing capacitor is charged and discharged with constant current sources between two voltage limits 


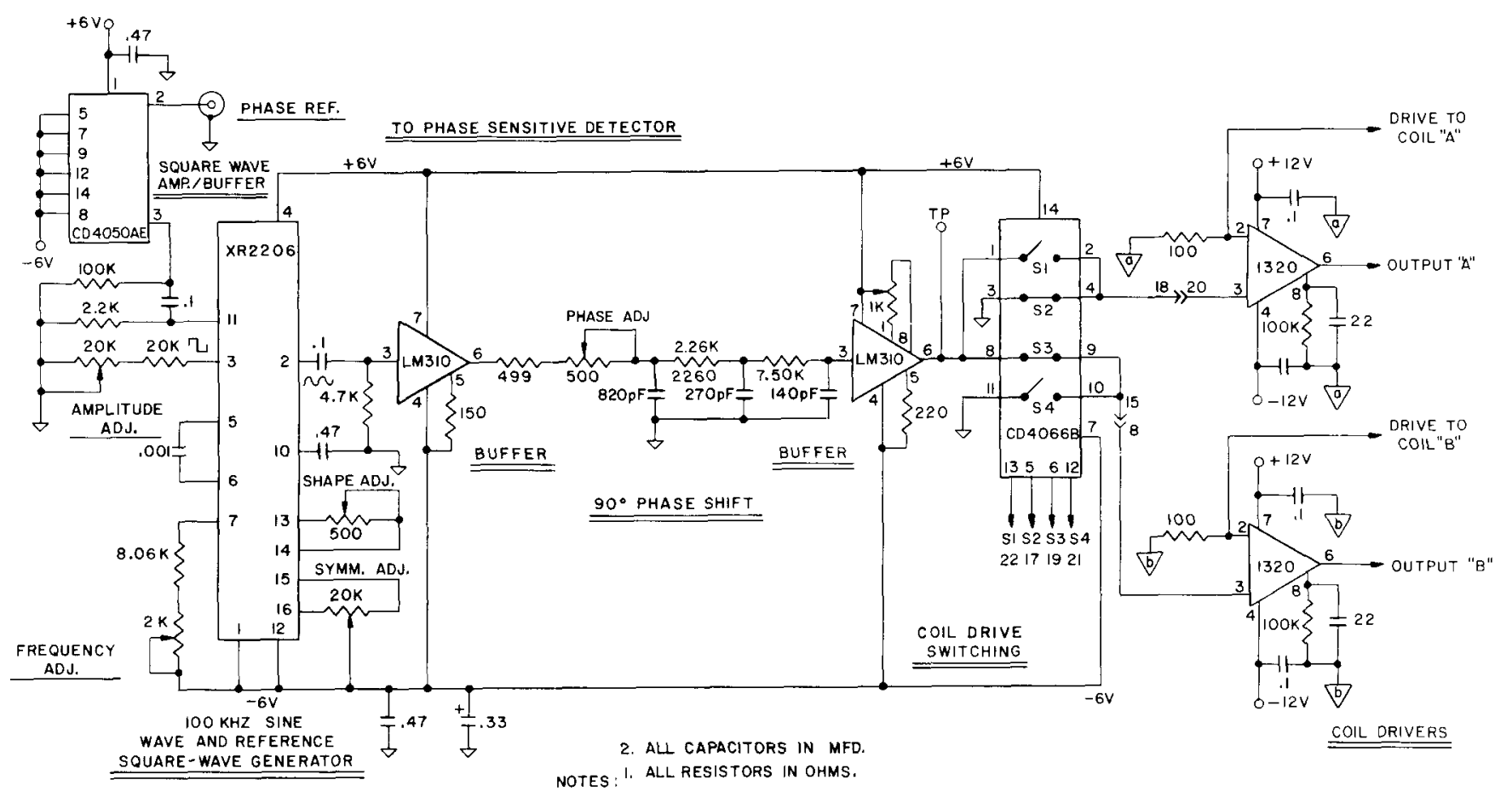

Fig. 2. Oscillator and coil driver circuitry.

sensed by a pair of internal voltage comparators. This process generates a trianguiar wave and a square wave. The square wave is taken out on pin 11 and passed through one section of the CD4050, which acts as a buffer amplifier, and the output is used as the $100-\mathrm{kHz}$ phase reference for the phasesensitive detector in the receiver section. The triangular wave is converted into an approximation of a sine wave inside the XR2206 by a shaping circuit. The sine-wave shape is optimized by means of the external symmetry and shape adjustments.

The sine-wave output from pin 2 of the XR2206 is passed through an LM3IO voltage follower, which acts as a buffer between the XR2206 output and the following low-impedance circuitry.

The sine wave is then phase shifted by $90^{\circ}$ in a three-section RC phase shifter, which also acts as a low-pass filter to remove much of the residual harmonic distortion in the signal. The $90^{\circ}$ phase shift is necessary since the phase-sensitive detector requires that the square-wave phase reference signal be in phase with the sine-wave phase component to be measured, and the XR2206 produces the square-wave and sine-wave output in phase quadrature. There is no practical way to phase shift the square wave, leaving as the only alternative to phase shift the sine wave.
The output of the phase-shift network is again buffered in an LM310 and then passed to the coiTdriver stages through a CD4066, which is a CMOS quad-analog switch. Two sections of the CD4066 are used with each coil driver to either pass through the sine-wave signal or to ground the input. The CD4066 switch control inputs, at CMOS logic levels, will come from the experiment sequencing circuitry.

The coil drivers are wideband op-amps operated in a voitage-to-current converter mode. The current sent to the transmitting coils is returned to the driver circuit through the return wire of the twisted-pair transmission line and is passed to circuit common through the 100- $\Omega$ resistor at pin 2 of the op-amp, which is the amplifier input. The amplifier action forces voltage balance between the sine-wave voltage input at pin 3 and the voltage produced by the current through the 100- $\Omega$ current sampling resistor at pin 2. The 1321 op-amp has sufficient voltage gain at $100 \mathrm{kHz}$ to force this conversion with negligible phase shift and distortion.

The transmitting coil inductance, which is several millihenries, is series resonated at $100 \mathrm{kHz}$ with a suitable capacitor to cancel its reactance as seen by the coil driver. The series resonant 
connection makes it possible to drive the coil with $10 \mathrm{~mA}$ at $100 \mathrm{kHz}$ with on $7 \mathrm{y}$ a few volts at the output of the amplifier to drive the current through the coil resistance, the sampling resistor, and the residual unbalanced reactance. The resonating capacitor is shunted by a $100-k \Omega$ resistor to provide a dc path for the feedback sufficient to keep the $\mathrm{dc}$ level at the amplifier output from drifting too far off zero.

\section{Amplifier and Phase-Sensitive Detector}

Phase relationships at the $100-\mathrm{kHz}$ working frequency must be very we 11 controlled throughout the system, since the major means for separating the eddy current response from the signal directly coupled by transformer action between the sending and receiving coils is by the fact that they are in phase quadrature. Most of the direct coupled signal is balanced by means of the cancellation coils so that it will not overload the amplifier, but there will be a residual quadrature-phase signal remaining because of the limitation on cancellation that can be practically achieved and

maintained. The phase-sensitive detector is used to reject the resicual quadrature signal. The phase-sensitive detector also functions as a means for reducing the noise bandwidth of the amplifier by means of the low-pass filter placed after the detector. Such a reduction in the effective bandwidth of the receiver amplifier is necessary to allow detection of the eddy current signals, which are in the tens of nanovolts range. The use of the phase-sensitive detector and post-detector filter to reduce the bandwidth allows the main $100-\mathrm{kHz}$ amplifier to be operated with a broad response centered about $100 \mathrm{kHz}$, and therefore, with only a graduat change in phase shift with frequency.

The receiver takes the outputs of the two sets of receiver coils, one at a time, through about $3.8 \mathrm{~m}(12 \mathrm{ft})$ of twisted pair line in a shield and terminated in about $100 \Omega$ at the end of the lines, as shown in Fig. 3. The two sets of coil signals are individually amplified in a low-noise and very well balanced differential input stage, with a constant-current-emitter current source for good common-mode rejection and cascode output for low phase shift. Signal passage through these two input stages is controlled by turning the constant-current sources on or off by means of cmos logic level signals from the experiment sequencer circuitry.

Ground reference for the coil signals is obtained by grounding the center taps of the coils to the shield common at the coils. No other ground is connected to the signal iines. It is expected that this configuration will avoid ground-loop-coupled

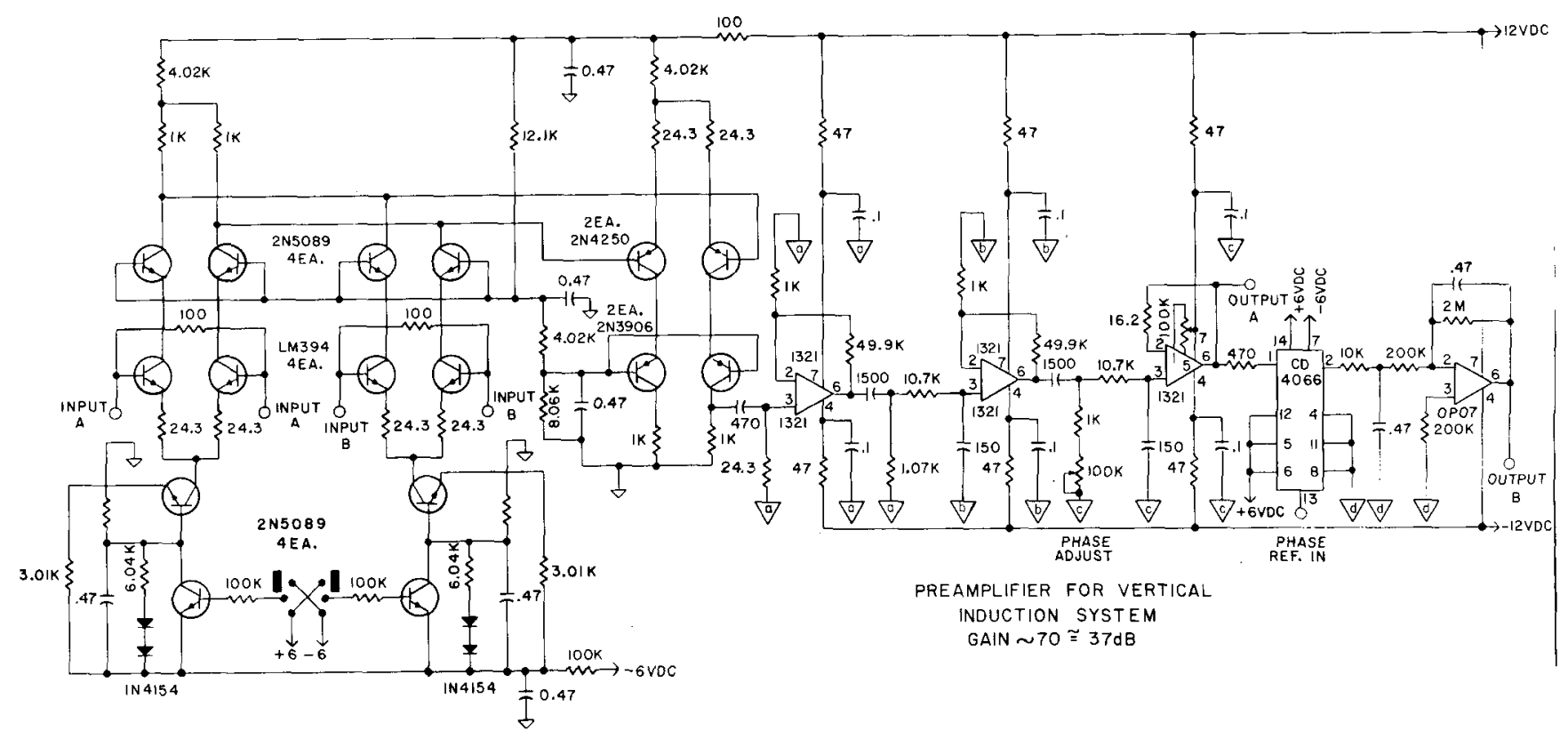

Fig. 3. Amplifier and phase-sensitive detector circuitry. 
noise problems. The differential input configuration allows this type of connection to be used. The input device is an LM194, which is a very well balanced transistor pair. The use of a constant-current source for the emitter current and the inherently well balanced transistor pair results

in high rejection of common-mode noise on the input signals.

The first-stage outputs are further amplified in another differential transistor pair with cas-

code outputs for low phase shift, and then taken off single ended with local ground reference to the main amplifier stages. The input amplifier configuration has, in addition to good rejection to common-mode input noise, good rejection to noise on the power supply lines. This is important to prevent phase shifts in the $100-\mathrm{kHz}$ signal caused by feedback through the supply lines.

The two input stages give a combined voltage gain of about $40 \mathrm{~dB}$ or a factor of 100 . The entire ac gain in the receiver is about $10^{6}$ or $120 \mathrm{~dB}$. Close control over the exact gain is not necessary, since the measurement made depends on the ratio of the outputs in the four measurement configurations rather than on the absolute level. Following the first input stage, the amplifier channel is common to all the measurement modes. The gains of the two input stages are mainily a function of the emitter current and the load resistors. Because the load resistor pair is shared by both input stages, the only separate elements controlling the gains are the emitter currents, and these are quite well controlled by the two constant generators.

The main ac amplification is done in three feedback stages using 1321 wideband op-amps. The first two stages provide $34-d B$ gain each and the last stage provides $24 \mathrm{~dB}$. The 1321 stages each produce a few degrees of phase lag at $100 \mathrm{kHz}$ because of the internal roll-off. The bandwidth of the amplifier is determined by the interstage coupling networks, which are set to produce both a lowfrequency and a high-frequency corner at $100 \mathrm{kHz}$, each with a $45^{\circ}$ phase shift in opposite directions for a net zero phase shift. The small phase shift from the op-amp stage itself is folded into the overall phase shift. One of the interstage couplings is made adjustable to allow trimming of the overall amplifier phase shift to zero at $100 \mathrm{kHz}$.
The net frequency response characteristic is a rather broad response centered at $100 \mathrm{kHz}$, with $3-\mathrm{dB}$ frequencies at $55 \mathrm{kHz}$ and $190 \mathrm{kHz}$, rolling off at about $12 \mathrm{~dB} /$ octave at the skirts. The broad response, while undesirable from the noise viewpoint, ensures that the phase shift is not sensitive to drifts in the coupling components. Low-TC capacitors and resistors are used for the coupling, further ensuring stability of the phase response.

The phase-sensitive detector is one section of a CD4066RN CMOS quad-analog switch acting as a series switch between the last ac amplifier stage and the output filter. The detector passes through either the positive or the negative half of an inphase $100-\mathrm{kHz}$ sine-wave signal, and the dc level of the output is approximately 0.9 of the rms ac signal level. It was found that a half-wave detector was sufficient and much simpler to implement than a full-wave detector. The phase-detector input is directly coupled to the last ac amplifier stage output and sees any dc component in this signa?. The last ac amplifier stage is provided with a dc offset control to zero the dc Tever in its output.

The phase-detector feedthrough from the switching input amounts to a few millivolts and is quite stable for a given device. This residual $d c$ from the switching noise can be zeroed out with the offset adjustment in the preceding amplifier. The dynamic range of the phase detector is from a millivolt (determined by the stability of its zero level) to several volts. In practice, much of the dynamic range will be used to accommodate the amplitude of the quadrature phase signal, which may be several times as large as the in-phase component of interest. The dc output due to the quadrature phase signal will be zero, leaving only the output due to the in-phase signal component.

Some low-pass filtering is done right after the phase-sensitive detector. The main low-pass filtering is done in the output stage by the RC network in the feedback path. The amplifier used, an OP-07, has very good dc stability and provides a low-frequency gain of 10 with a single-pole low-pass rolloff with a 1-s time constant.

\section{E. Coil Sets}

To produce synthetic electronic coil rotation, two identical coil sets are required. Each set consists of three separate coils, and the planes of 
the coil sets must be oriented $90^{\circ}$ from each other. Also, the center of each coil must coincide with the center of its perpencicuiar twin. The coils must also have metal shields around them (Faraday shields) except for a gap. The purpose of the shields is to eliminate the large, unwanted capacitive coupling signals that will be present otherwise.

Multiturn circular coils presented significant mechanical and electrical difficulties. Coil selfresonance was at a low frequency, which is undesirable. It was also difficult to adjust and shield the coils, and placement of required cable runs presented further problems.

A second construction technique was tried and has been more successful. This alternate arrangement makes more efficient use of space, permits easier adjustment of individual coils, allows installation of adequate shielding, and provides adequate space for cabling. Each individual coil was broken into two rectangular coils, each $7.6 \mathrm{~cm}$ ( $3 \mathrm{in.}$ ) by $15.2 \mathrm{~cm}$ ( $6 \mathrm{in.}$ ), wired in series and held $8.3 \mathrm{~cm}(3-1 / 4 \mathrm{in.})$ apart.

The transmitter and receiver coils were wound with 55 turns ( 5 layers of 11 turns), and the bucking coils contained seven turns. Each coil was series-resonated with capacitors held in place on the dielectric crossbar. These coils can be mounted perpendicular to an identical set more easily than the circular coils. Coil pairs were placed apart at vertical distances of $76.2 \mathrm{~cm}(30 \mathrm{in.})$ in the Taboratory prototype. The center tap of the receiving coils was grounded, to be compatible with the receiver.

The laboratory unit was used to verify the analys is and to demonstrate the capability of measuring fracture direction without mechanical rotation. During these tests and demonstrations, it was found that grounding methods were extremely important and that the shielding provided by thin copper foil was marginal. It is anticipated that a good deal of attention to these details will be required as the actual construction begins.

\section{F. Magnet ic North Sensor}

The vertical induction log requires a means of determining the orientation (azimuth) of the tool once it is downhole. It has been proposed that a flux-gate magnetometer, located in the tool, be used to measure the orientation of the tool with respect to the earth's magnetic field. If the assumption is made that the boreholes to be logged are all nearly vertical and that the magnetic fields in the rock are primarily caused by the earth's field, then a single-axis magnetometer located within the tool and in a plane perpendicular to the tool axis will be sufficient. For best accuracy the magnetometer should be free to remain in a plane perpendicular to the earth's gravitational field (pendulum mounting) and must be located in a portion of the tool free from magnetic effects or magnetic shielding.

The commercial instrument that most nearly satisfies the above requirements and those requirements imposed by the tool design is the Model FDO60101-1 magnetic flux detector manufactured by Humphrey, Inc., of San Diego, California. This instrument requires an excitation of $28 \mathrm{Vdc}$ at a maximum current of $200 \mathrm{~mA}$. The output voitage is 2.5 times the sine of the heading with respect to magnetic north. Its upper operating temperature limit is $70^{\circ} \mathrm{C}$. A complete list of operating characteristics is included on the enclosed drawing (Fig. 4). One basic limitation of this instrument is that zero output is obtained for north and south orientations.

As supplied, the standard instrument exceeds one dimension (diameter) of the dewar proposed for the induction log. Harold Kries of Humphrey, Inc. has indicated that a modified flux detector can be supplied which will not exceed $5.8-\mathrm{cm}-(2.28-i n .-)$ diam over its entire length. The modified instrument could be supplied in approximately 8 wh at a cost of approximately $\$ 1500$.

G. A/D Converter, Multiplexer, and Line Driver

1. Purpose. The downhole data link was designed to provide a serial data communication link between downhole experimental units and surface data-acquisition electronics. The unit is capable of receiving 16 analog signals, within the range of $\pm 5.25 \mathrm{~V}$ and one 5-bit binary data word. Output information is in ASCII 7-bit code format and contains a carriage return (CR) and line feed (LF) as frame termination characters.

\section{Description.}

a. Physical. The unit is packaged to fit in a 7.1-cm- (2.8-in.-) diam tube and occupies approximately $25 \mathrm{~cm}^{3}\left(10 \mathrm{in} .^{3}\right)$. 

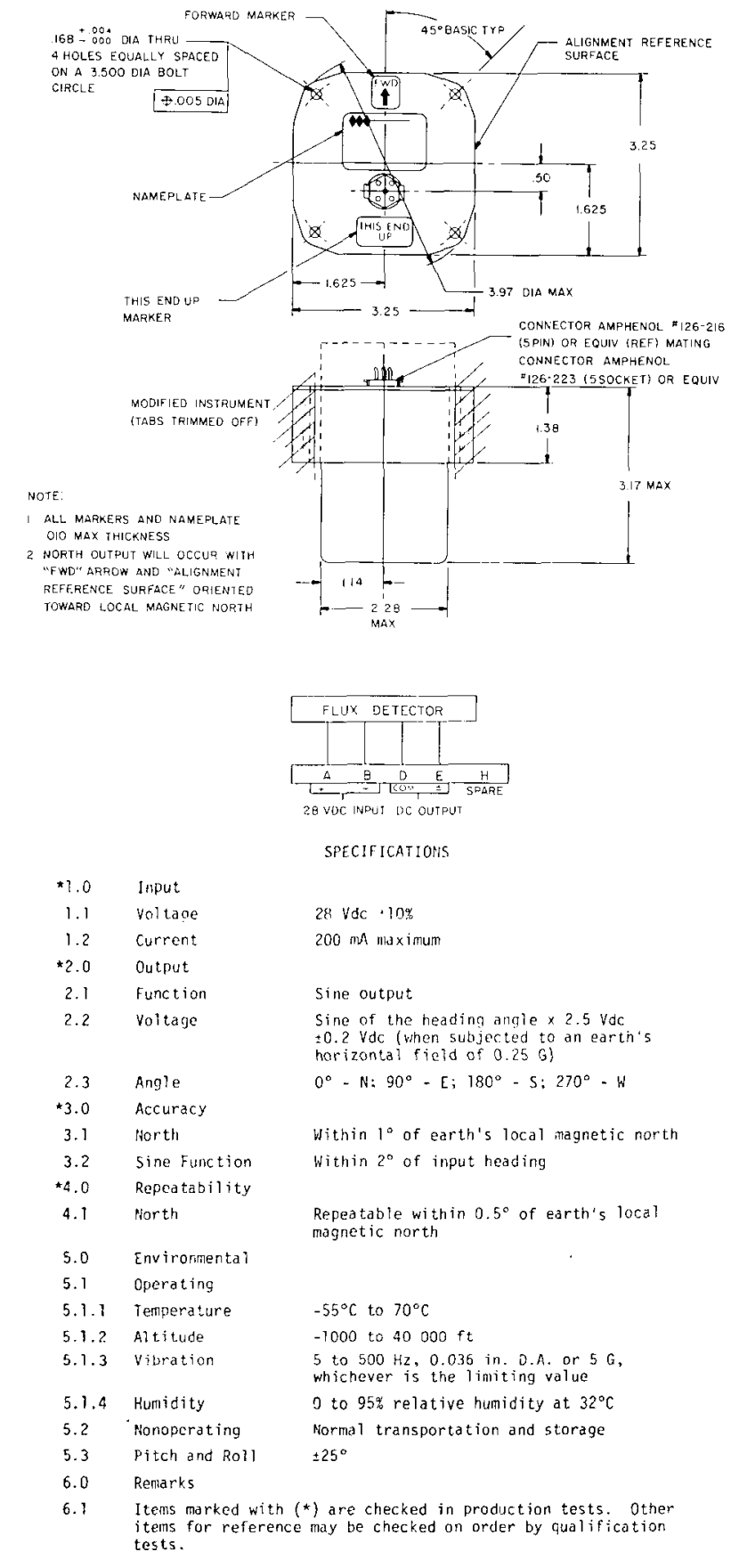

Fig. 4. Mechanical schematic of a Humphrey, Inc., flux gate magnetometer (electronic compass).

\section{b. Electrical.}

Basic operation: Refer to Fig. 5 for unit configuration and Fig. 6 for operational times.

A frame of output data is initiated by a 1-s frame synchronization during which time no data are transmitted. Following this frame synchronizing pulse a 16-channel multiplexer provides: (1) zero or $+2.50-V$ calibration data, or (2) one of 14 analog signals to a 12-bit $A / D$ converter. The $A / D$ converter signals are converted into two data bytes (most significant data first), via 6-bit parallel tristate bus drivers (during $B C I$ and $B C 2$ times, respectively). The data bus is received by a UART and converted to serial data transmitted in ASCII format at a 110-baud rate.

Following the 16 channels of analog (A/D) data, a 5-bit binary data word is received from the outside word and placed on the data bus during $B C 3$ time. A sixth bit (MSB) of logical "7" is added to received binary data for format reasons, and the results are placed on the data bus via tristate bus drivers. These data are transmitted twice for redundancy.

The last two data words are: ASCII carriage return (CR, BC4 time) and line feed (LF, BC5 time). $B C 5$ concludes the basic frame of data, transmission time approximately $4.6 \mathrm{~s}$ (including the $1-\mathrm{s}$ frame synchronizing pulse). $B C 5$ is buffered to produce end of frame (EOF) for use by external units.

c. Detailed Operation.

Major Timing Operations: Figure 7 shows in detail the action timing of the control signals with respect to each other.

A frame of data is initiated by a 1-s one-shot during which time data transmission is inhibited. This signal is used: (1) to trigger the $A / D$ converter 60- $\mu \mathrm{s}$ initiate conversion pulse (IC), and (2) to provide a frame synchronizing pulse reset for the 16-channel MUX-control signals $(\mathrm{CO}, \mathrm{Cl}, \mathrm{C} 2, \mathrm{C} 3$, and $(4)$, and the DS and SC flip-flops.

The UART data strobe (DS) enters data into the UART input buffer when (1) the A/D conversion is concluded (ADCBZL) and (2) the UART output register is empty (TRMT). The DS pulse rate is divided by 2 to produce SC, which advances the MUX control scaler (CO through C4). During $\mathrm{CO}$ time, bus driver control signals $B C l$ and $B C 2$ are produced and they place the $A / D$ converter 12-bit data on the data bus lines BDO through BD6. The most significant byte (MSB) is enabled during $B C I$ time, the least significant byte (LSB) during $B C 2$ time. Thus, the MSB is serially transmitted first.

After 16 channels of analog data have been scanned, $B C 3$ time is entered and the 5-bit binary data word is placed on the data bus. To insure that 


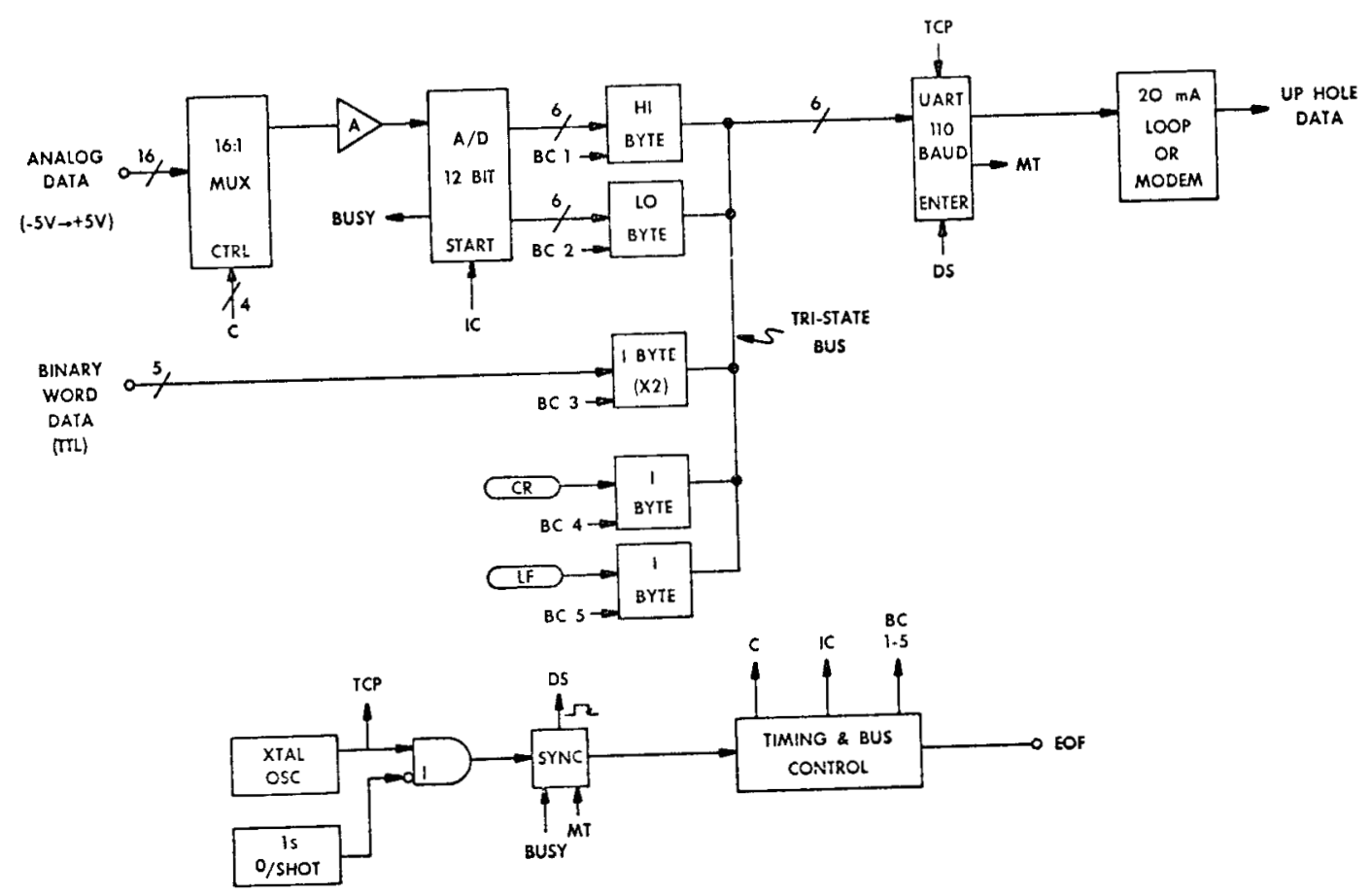

Fig. 5. Downhole data link.

PURST

is

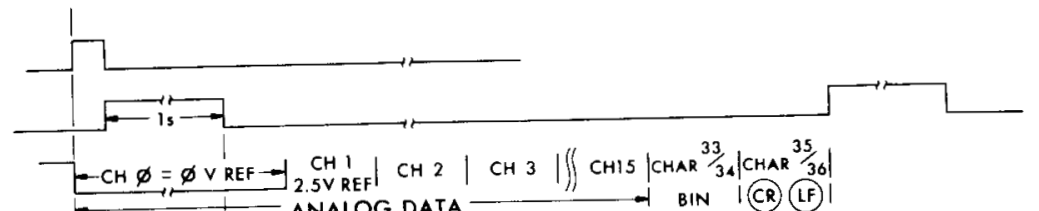

CHANNEL

$\mathrm{BCl}$

$\mathrm{BC2}$

BC3

BC4

BC5

DS

IC

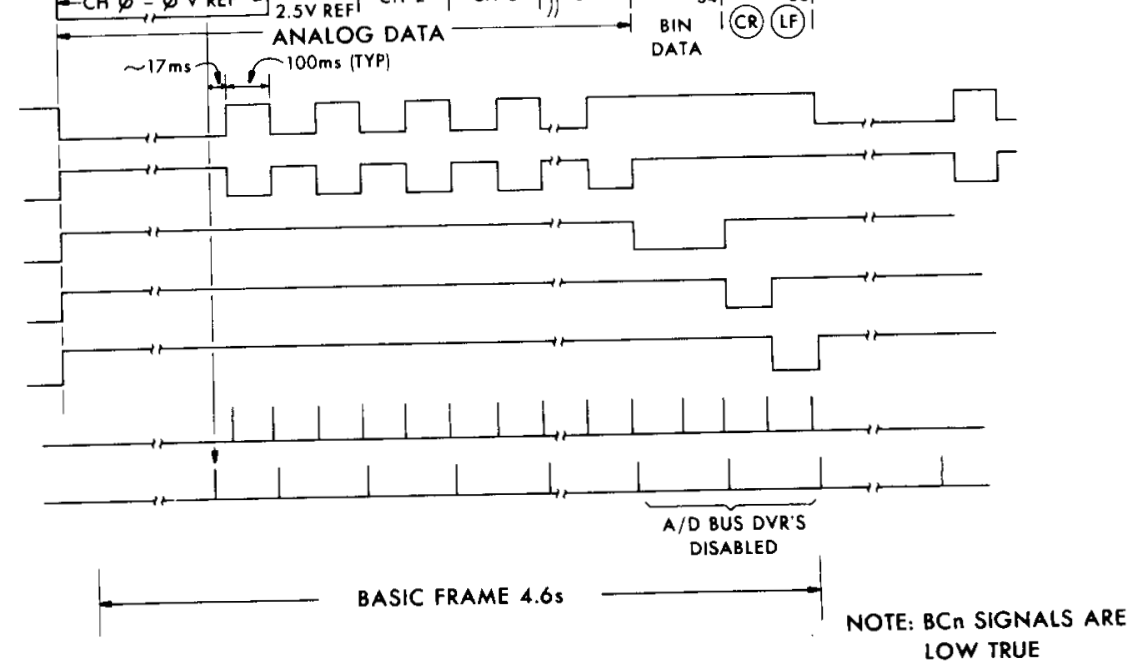

Fig. 6. Major timing. 


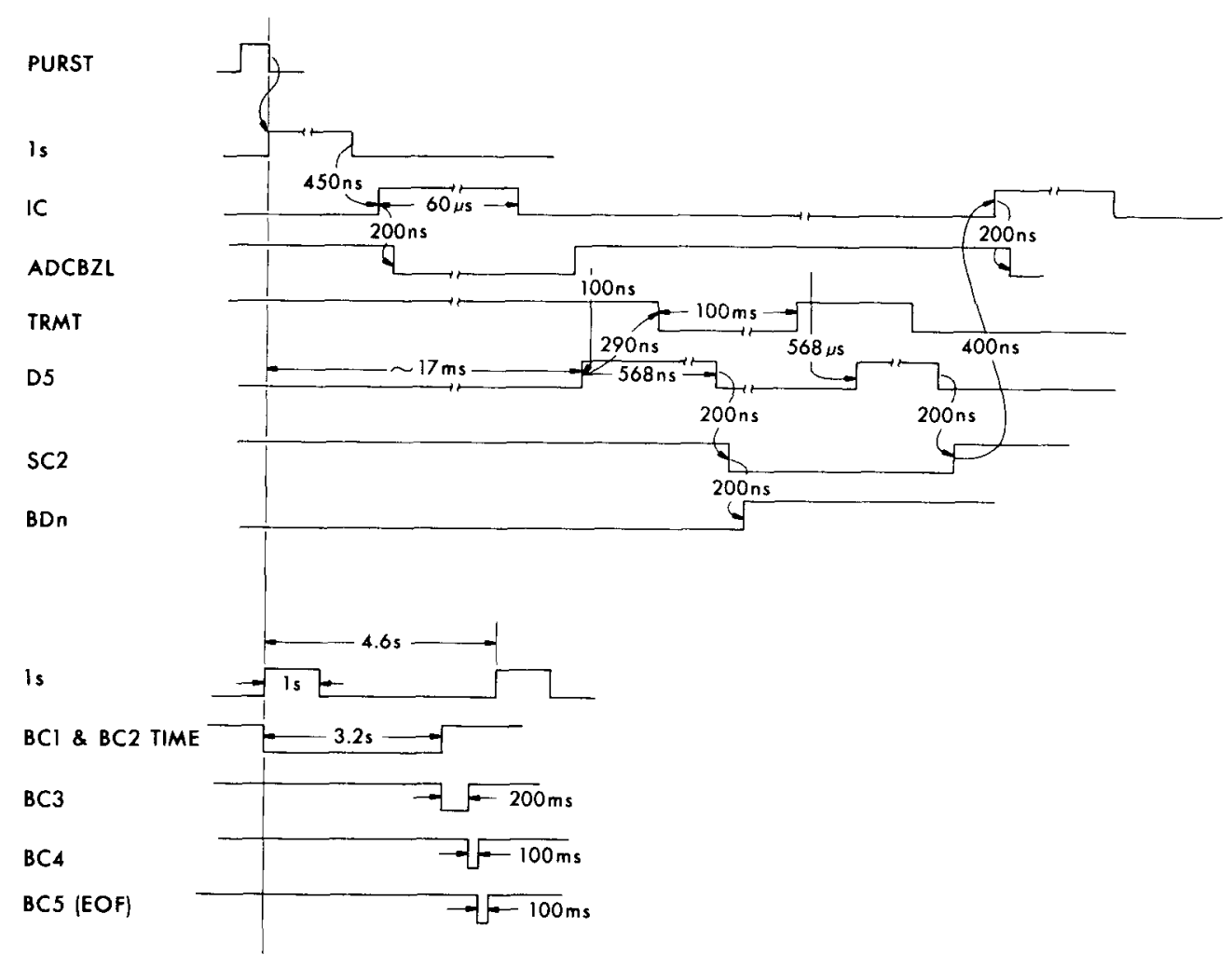

Fig. 7. Detailed timing.

ASCII control characters are not transmitted, bit 6 (BD5) is hard-wired to a logical "?." Thus, ASCII vaiues of this data range from 040 through 077 (OCta1). These data are transmitted twice for redundancy.

Following $B C 3$ time, the ASCII values for $C R$ and $L F$ are placed on the data bus during $B C 4$ and $B C 5$ times, respectively. An EOF signal is produced from BC5 for use by peripheral equipment. This signal is low-time DTL, capable of sinking $20 \mathrm{~mA}$ and sourcing +6 Vdc through $570 \Omega$.

Analog Data Amplifier: Incoming analog information ( $\pm 5.25 \mathrm{~V}$ range) must be converted into a 0 - to $+10 \mu \mathrm{A}$ signal for analys is by the 12-bit $A / D$ converter.

The 16-channel MUX analog output (MAO) is first buffered by a voltage follower to provide high-input impedance $(<10 \mathrm{M})$. Two amplifier sections, with a fixed overall gain of 0.75 subsequently perform the level conversion producing 0 to $+10 \mu \mathrm{A}$ for the $A / D$ converter (A/D IN). Adjustments are provided to (1) adjust the amplifier to midscale $(4.00 \mathrm{~V})$ with $0.00 \mathrm{~V}$ input (POT 1), (2) adjust the ampli- fier gain to 0.75 (L.S. resistor), and (3) adjust the $A / D$ converter signal current input $(0$ to $10 \mu \mathrm{A})$ (ADIN) (for $M D O=0.00 \mathrm{~V}$ ) for an A/D output of 1000 (octa1).

Serial Output Data Format: Serial output data from the unit are intended to be displayed on a standard 20-mA current loop teletype and/or received by a computer $\mathrm{I} / 0$ interface capable of receiving serial ASCII 20-mA current loop data. The 20-mA source must be provided by the surface electronics to make the output buffer compatible with either an active or passive TTY terminal.

Analog Data: Format of the converted analog data has been chosen to eliminate unprintable TTY characters. This is accomplished by manipulation of bit 7 (BD6) in the transmitted ASCII word. (BD6 $=B D 5 \times C 4$, where $C 4$ is true during $B C 1 / B C 2$ time). Thus, the data received by the TTY terminal always result in a unique printable character as a function of the analog input signal. The voltage represented by the printed characters is shown in Table I. 
TABLE I

CHARACTER CONVERSION TABLE VOLTAGE VS HI (LO) BYTE CHARACTER

HI Byte

\begin{tabular}{|c|c|c|c|c|c|}
\hline $\begin{array}{l}\text { + Volts } \\
\text { Char } \\
\end{array}$ & Volts & $\begin{array}{l}\text { - Volts } \\
\text { Char } \\
\end{array}$ & $\begin{array}{l}\text { + Volts } \\
\text { Char } \\
\end{array}$ & Volts & $\begin{array}{c}\text { - Volts } \\
\text { Char } \\
\end{array}$ \\
\hline$S P$ & 0.00 & & a & 0.000 & $?$ \\
\hline$!$ & 0.16 & & A & 0.005 & \\
\hline$"$ & 0.32 & & $B$ & 0.010 & $=$ \\
\hline$\#$ & 0.49 & & $c$ & 0.015 & \\
\hline$\$$ & 0.66 & & $D$ & 0.020 & ; \\
\hline$\%$ & 0.82 & & $E$ & 0.025 & : \\
\hline$\&$ & 0.98 & $Y$ & $F$ & 0.030 & 9 \\
\hline 1 & 1.74 & $x$ & $G$ & 0.036 & 8 \\
\hline 1 & 1.31 & $W$ & $H$ & 0.041 & 7 \\
\hline ) & 1.47 & V & I & 0.046 & 6 \\
\hline * & 1.64 & U & $\mathrm{J}$ & 0.051 & 5 \\
\hline+ & 1.80 & $T$ & $k$ & 0.056 & 4 \\
\hline , & 1.97 & $S$ & $L$ & 0.061 & 3 \\
\hline- & 2.13 & $R$ & $M$ & 0.066 & 2 \\
\hline . & 2.33 & $Q$ & $N$ & 0.071 & 1 \\
\hline \multirow[t]{2}{*}{1} & 2.46 & $P$ & 0 & 0.076 & \\
\hline & 2.62 & 0 & $P$ & 0.082 & $/$ \\
\hline 1 & 2.79 & $N$ & Q & 0.087 & . \\
\hline 2 & 2.95 & $M$ & $R$ & 0.092 & - \\
\hline 3 & 3.17 & $L$ & $S$ & 0.097 & , \\
\hline 4 & 3.28 & K & $T$ & 0.102 & + \\
\hline 5 & 3.44 & $\mathrm{~J}$ & U & 0.107 & * \\
\hline 6 & 3.61 & I & V & 0. & ) \\
\hline 7 & 3.77 & $H$ & $W$ & 0.117 & 1 \\
\hline 8 & 3.94 & G & $x$ & 0.122 & ' \\
\hline 9 & 4.10 & $F$ & $y$ & 0.127 & $\&$ \\
\hline : & 4.26 & $E$ & & 0.132 & $\%$ \\
\hline \multirow[t]{2}{*}{; } & 4.43 & $D$ & & 0.137 & $\$$ \\
\hline & 4.59 & C & & 0.143 & $\#$ \\
\hline \multirow[t]{2}{*}{$=$} & 4.75 & B & & 0.148 & $"$ \\
\hline & 4.92 & $A$ & & 0.153 & $!$ \\
\hline$?$ & 5.08 & e & & 0.158 & $S P$ \\
\hline
\end{tabular}

To use this table, first determine the printed characters (high and low byte) for the desired analog channel. then sum the voltages represented by the characters.

Binary Data word: The last two printed characters on a line represent the 5-bit binary data word received by the system. Bit 6 (BD5) is hard-wired to a logical "l" so that all values of the word are printable characters. This information is transmitted twice for redundancy. Thus, the ASCII values range from 040 (octal) for a binary word value of 00000 to 077 (octal) for a binary word value of 11111 . Printed characters range from SP through ?. An example is shown in Fig. 8.

d. Uphole Transmission Link. Two techniques are available for transmitting serial data uphole. The most straightforward is to transmit 20-mA ASCII data. Circuitry required for this technique is a pair of transistors, the output stage capable of sinking $20 \mathrm{~mA}$.

There is some uncertainty concerning RFI that may interfere with sensitive downhole units (that is, the magnetometer) from switching the 20-mA current. A second scheme would reduce this problem, but lack of experimental data results makes judgment difficult.

The second technique relies on modulating a low-speed modem transmitter with the serial data from the UART (SO). The modem output is a sine wave whose frequency is a function of the modulation information. A logical " 7 " produces $2025 \mathrm{~Hz}$ and a logical "O" (marking) produces $2225 \mathrm{~Hz}$. Demodulation of the modem signal will be done on the surface and the 20-mA loop signal for the TTY terminal is provided in the demodulator package.

3. Electrical Specifications.

a. Input Signal Conditioning. The integrated circuits used in the downhole data link are C-MOS. Input terminals that interface with the outside world have nominal protection in the form of (1) $1 \mathrm{k} \Omega$

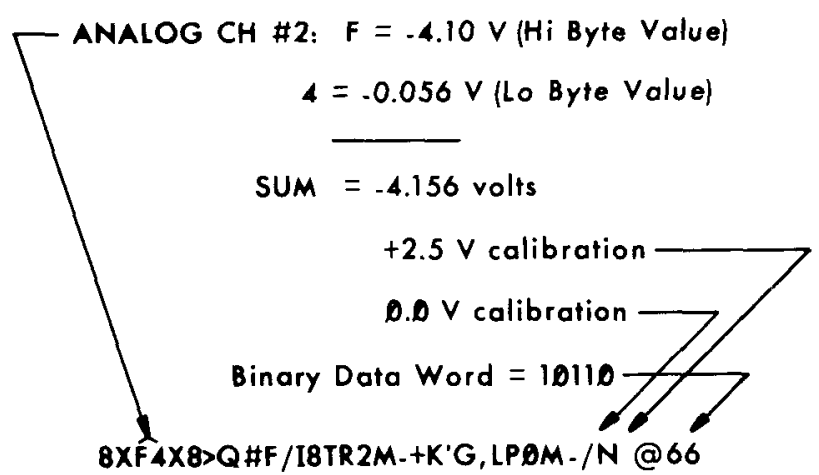

Fig. 8. A TTY line example. 
series resistors in the analog input section and (2) iks series resistors with diode clamps to +6 and ground in the binary data word section.

Input voltage levels should be limited to (1) $\pm 7 V$ to the analog section, and (2) +7 and $-7 V$ to the binary data word section. Input impedance to both sections, within the above ranges, is $>10 \mathrm{M} \Omega$.

b. Input Power. Input power to the unit is: $+6 \mathrm{Vdc}$ ? $30 \mathrm{~mA}$

$-6 \mathrm{Vdc} \quad-2.5 \mathrm{~mA}$

+12 Vdc $01.5 \mathrm{~mA}$

-12 Vdc $\approx-2.5 \mathrm{~mA}$

Total input power $<250 \mathrm{~mW}$ nominal.

4. Circuit Diagrams. The circuit diagrams are provided in Figs. 9 through 12.
VI. SUMMARY

Several main items of electronic effort remain. First, the controller/sequencer must be designed. Because the experiment sequence and requirements will be influenced by the mechanical design as well as the analytical requirements, it was felt that sequencer design was presently premature. This design is straightforward and minimal once the actual experiment sequence is determined.

Second, a large amount of interfacing and check-out remains. Again, this effort depends in part on the mechanical design and components used. Interfacing the oscillator, coil driver, coil sets, and receiver has been accomplished.

Third, the ruggedized electronics must be built and tested. Again, this effort awaits mechanical design for sizes, cable routings, etc. No major problems are anticipated in this effort, however.

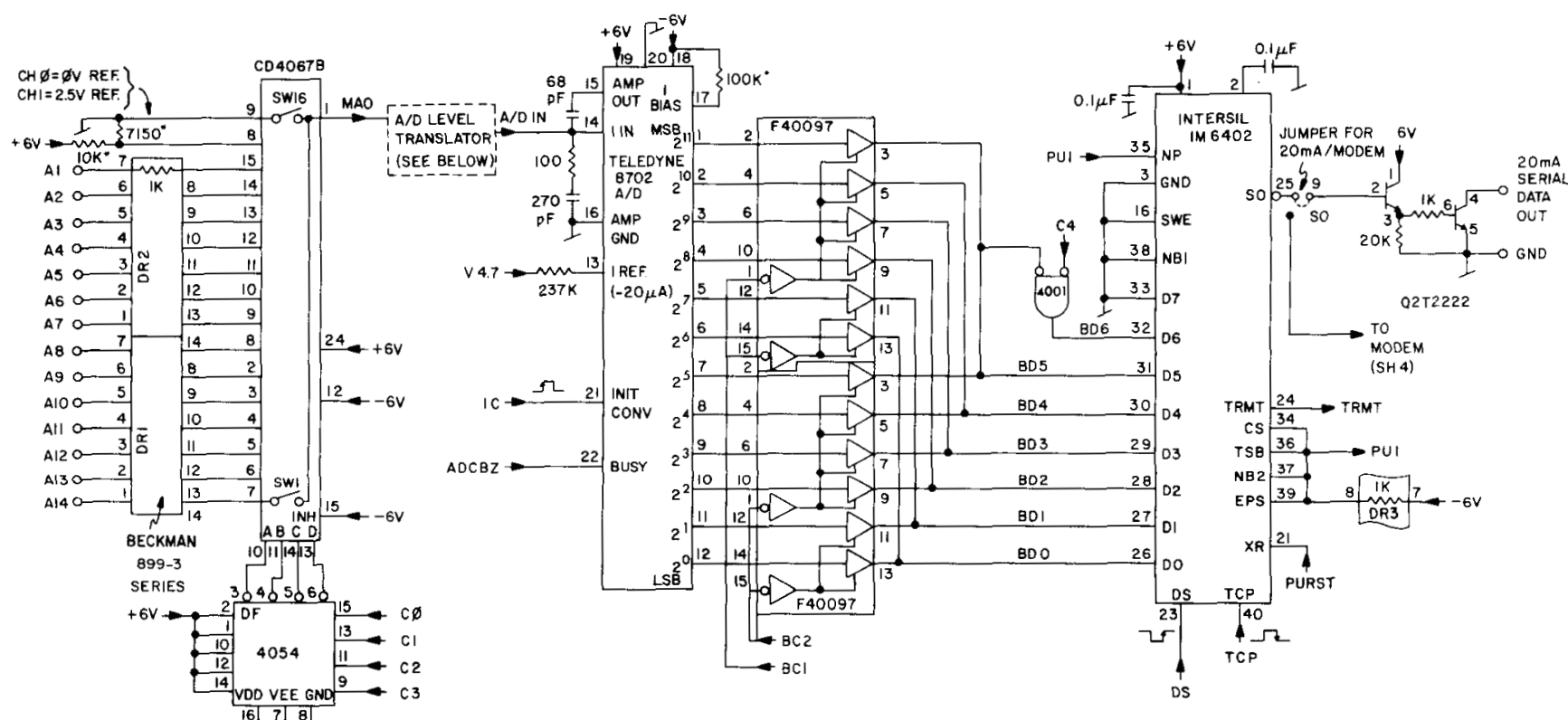

16) $7 / 28$

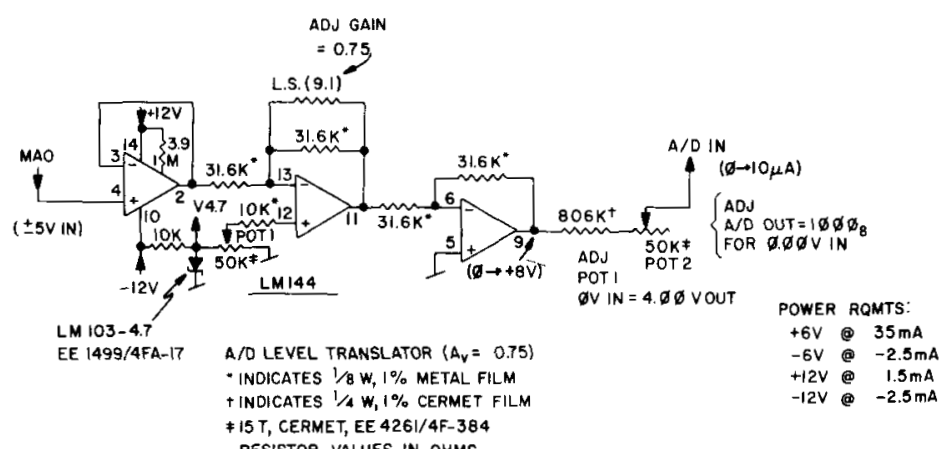

NOTE: CD4049:

+6: PIN 1

GND: PIN 8

Fig. 9. Multiplexer and A/D converter circuitry. 


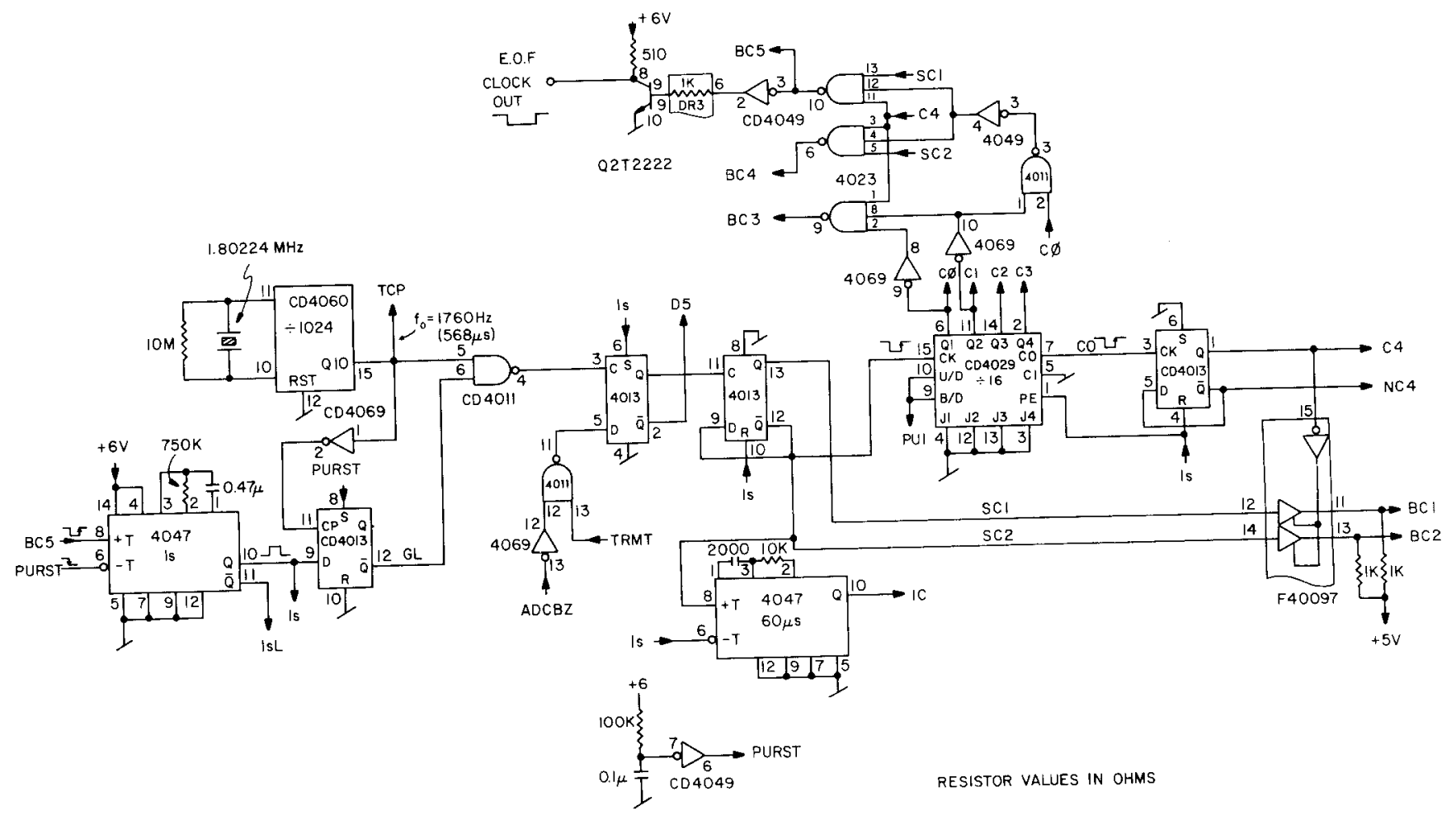

Fig. 10. Timing circuitry.

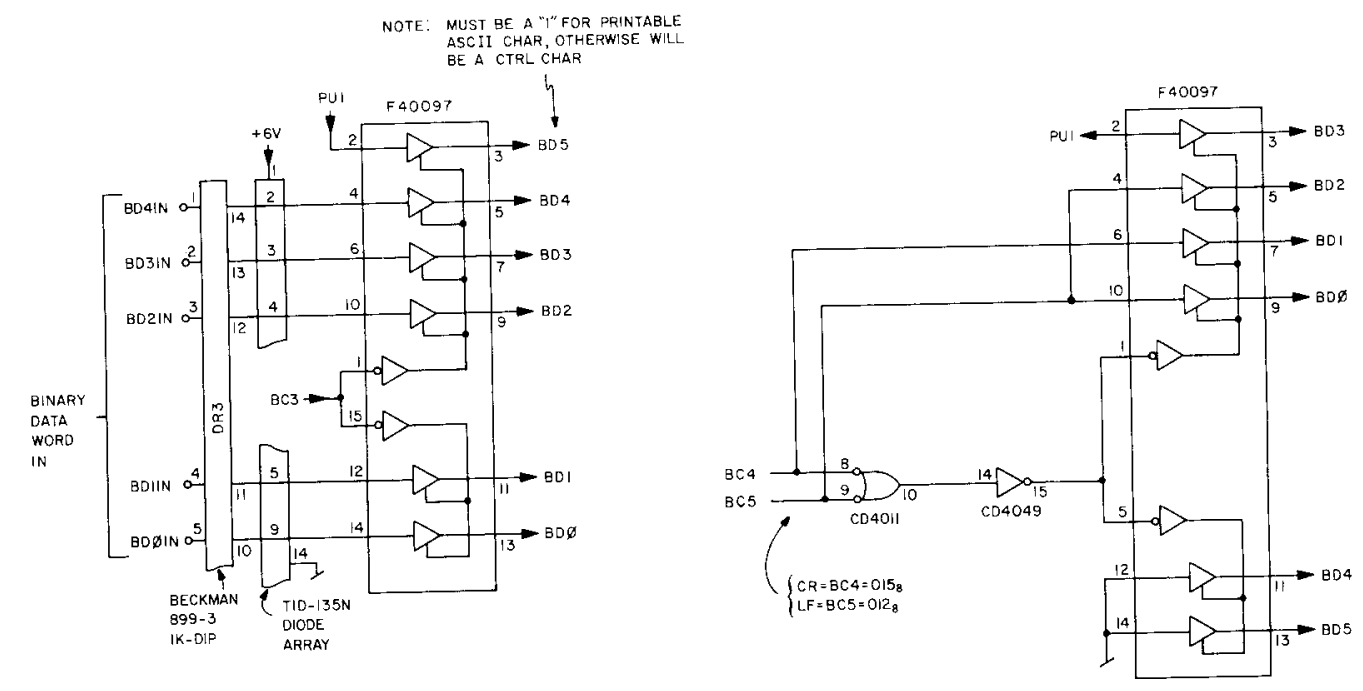

Fig. 11. Coder and line-driver circuitry. 


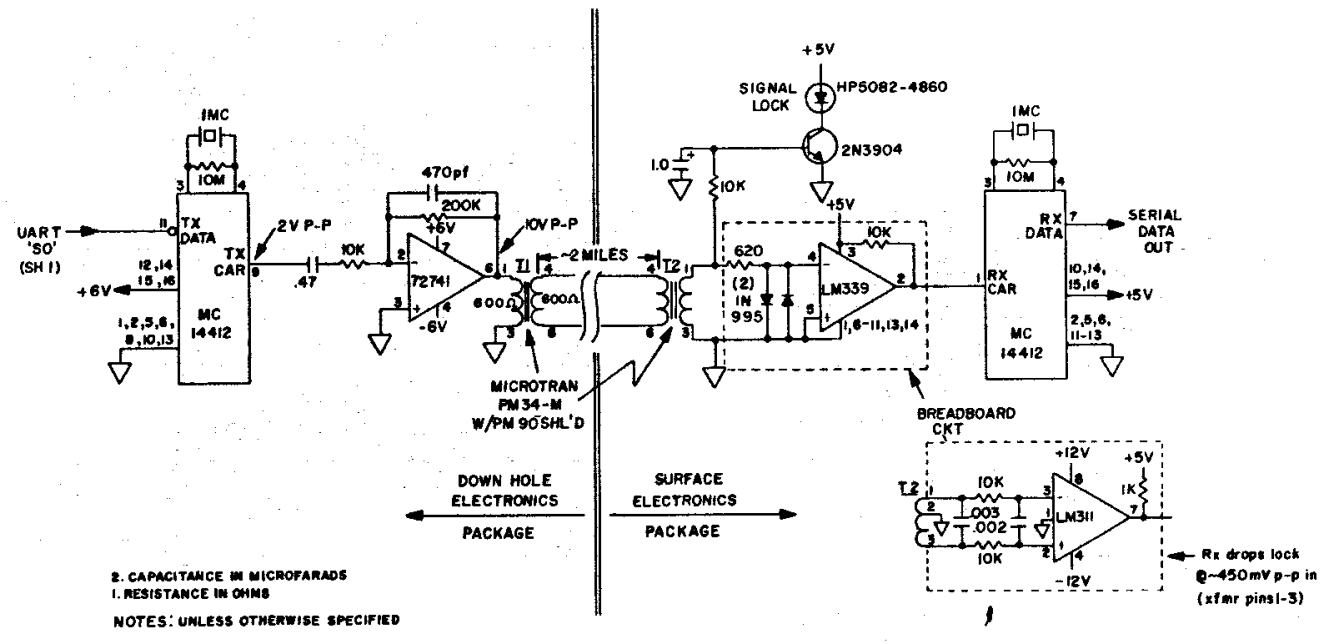

Fig. 12. Optional modem circuitry.

Last, the components must be mated to the mechanical housing, and the entire instrument will be performance tested before lowering into the intended hostile environment.

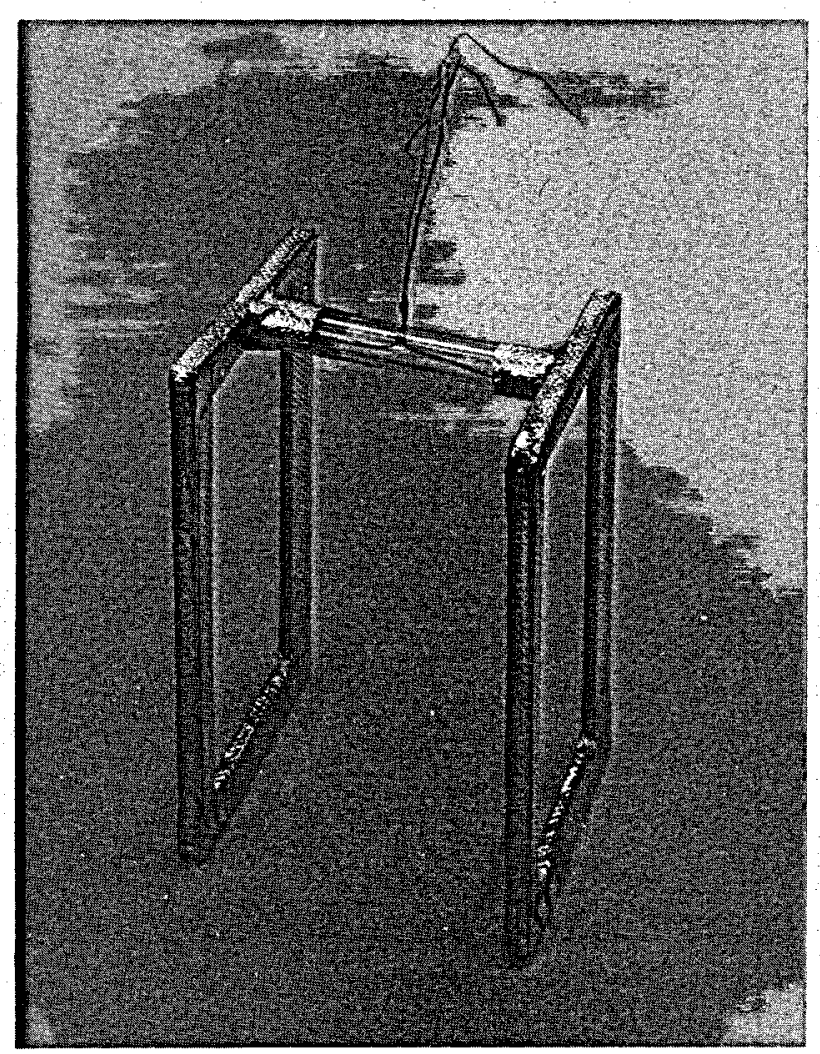

Fig. 13. A shielded rectangular coil set.
Figures 13 through 20 provide visualization of existing prototype hardware.

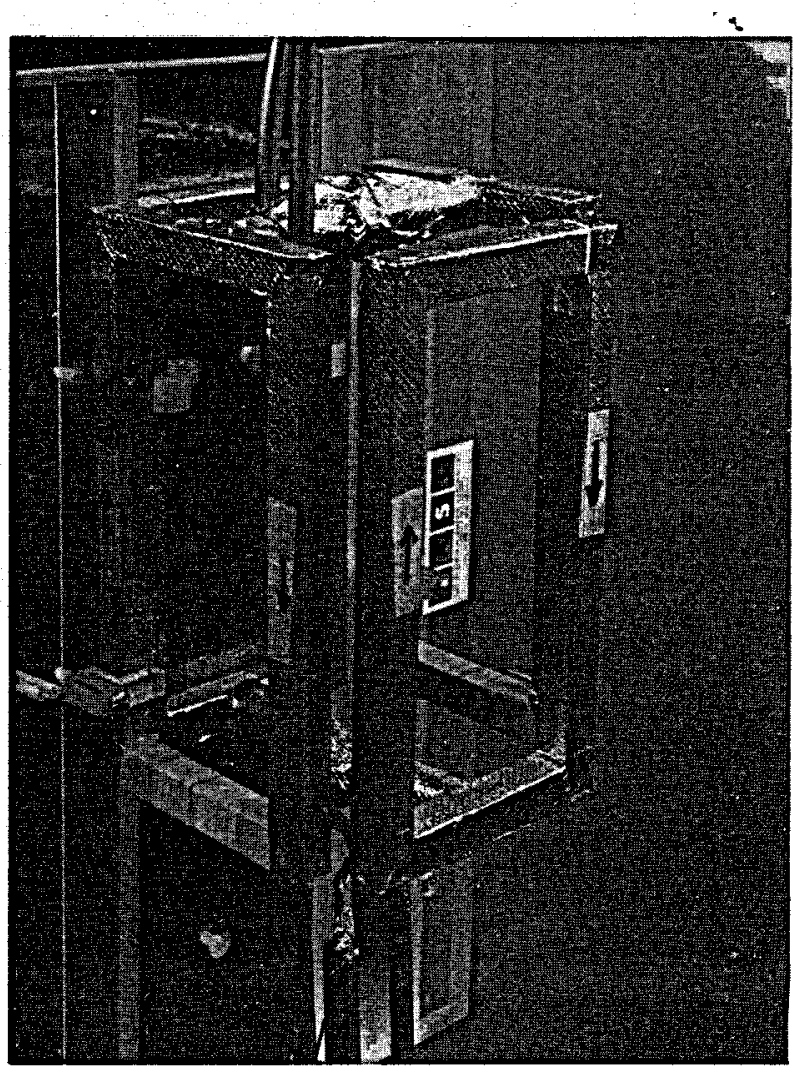

Fig. 14. Two shielded rectangular coil sets mounted perpendicularly to each other. 


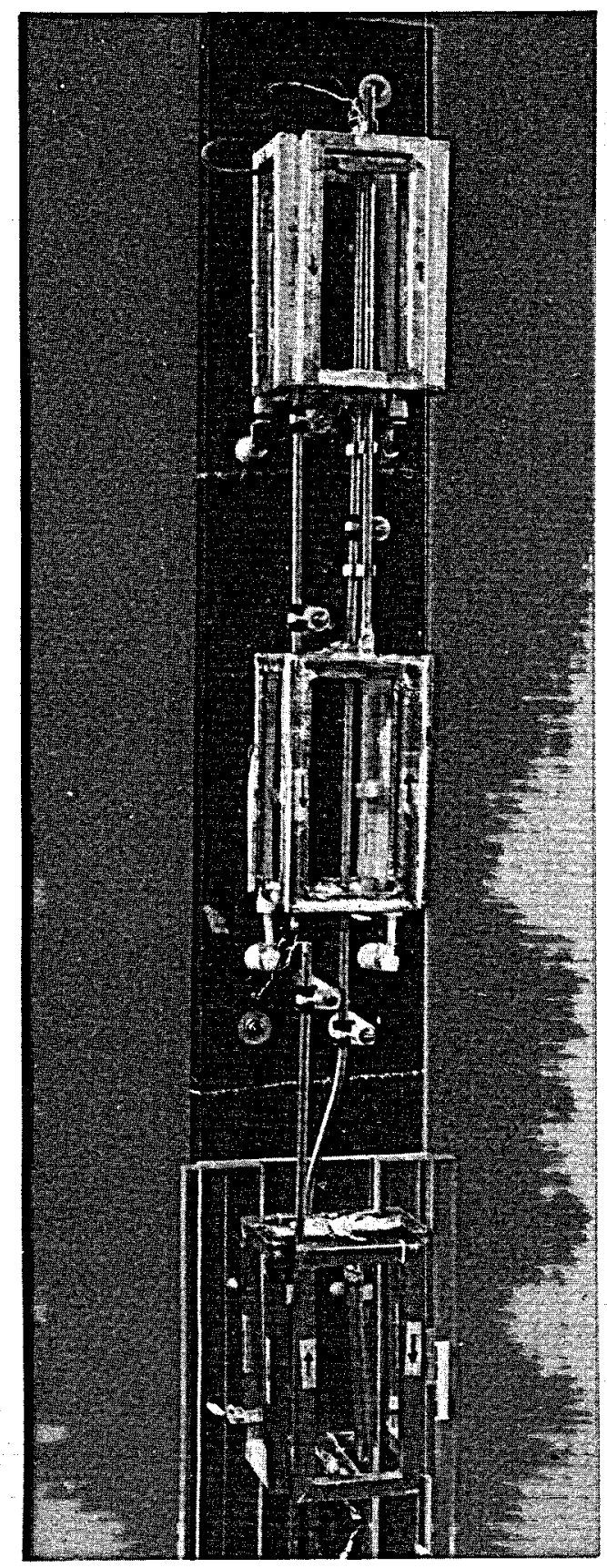

Fig. 15. Transmitting (top), bucking (middle), and receiving (bottom) rectangular coils for electronic rotation.

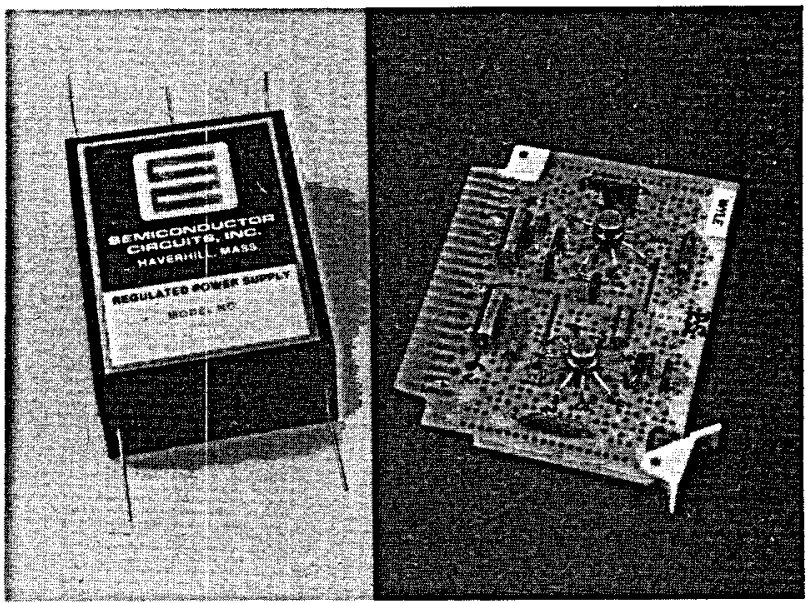

Fig. 16. Power supply and $\pm 6-V$ regulator breadboard.

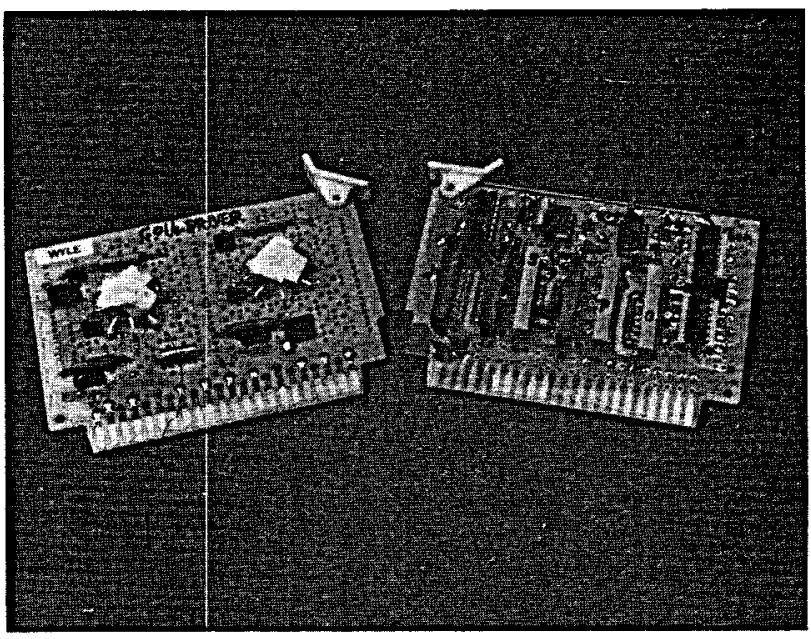

Fig. 17. Oscillator (right) and coil driver (left) breadboards.

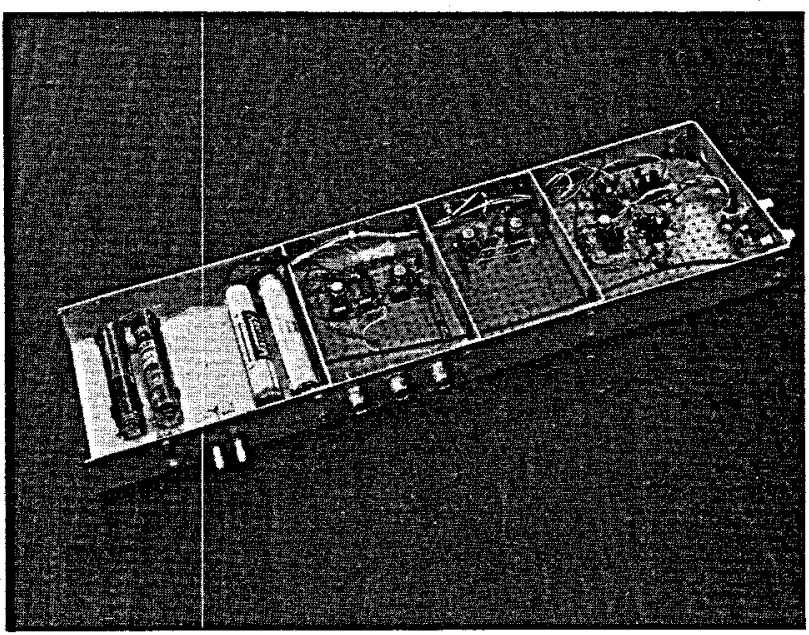

Fig. 18. Dual-channel amplifier and phase-sensitive detector breadboards. 


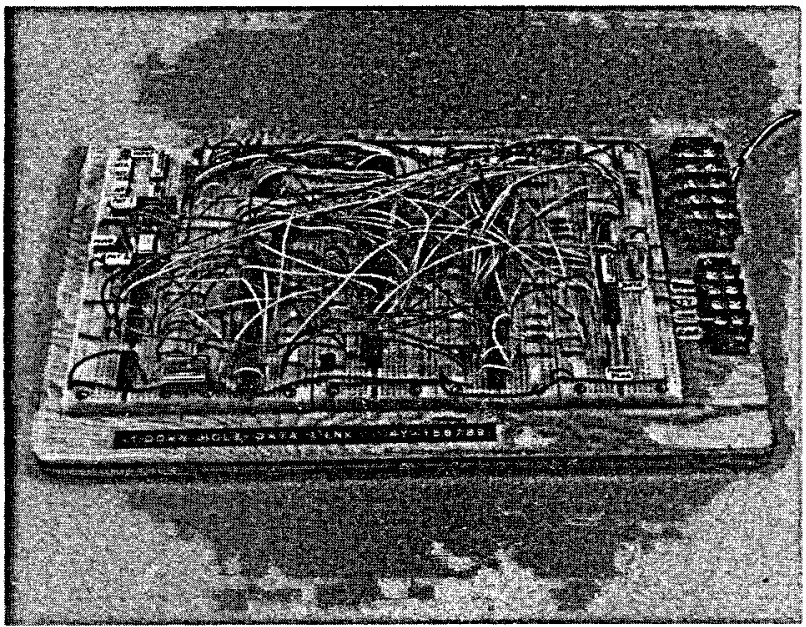

Fig. 19. A/D converter, multiplexer, and line driver breadboards.

\section{ACKNOWLEDGMENTS}

This instrument was originally conceived at LASL by $P$. Kintzinger, F. West, and W. Johnson. The support of J. Rowley and A. Blair have been vital to the continued development of this instrument. The dedicated work of J. Neudecker, A. Shapolia, and P. Salazar are also gratefully acknowledged.

\section{REFERENCES}

1. "The Los Alamos Scient ific Laboratory's Dry Hot Rock Experiment: Engineering and Scientific Studies," a series of papers by LASL HDR staff presented at the 1976 Spring Meeting of the American Geophysical Union, Washington, DC Apri1 12-15, 1976.

2. J. A. Landt, J. C. Rowley, J. W. Neudecker, and A. R. Koelle, "A Magnetic Induction Technique

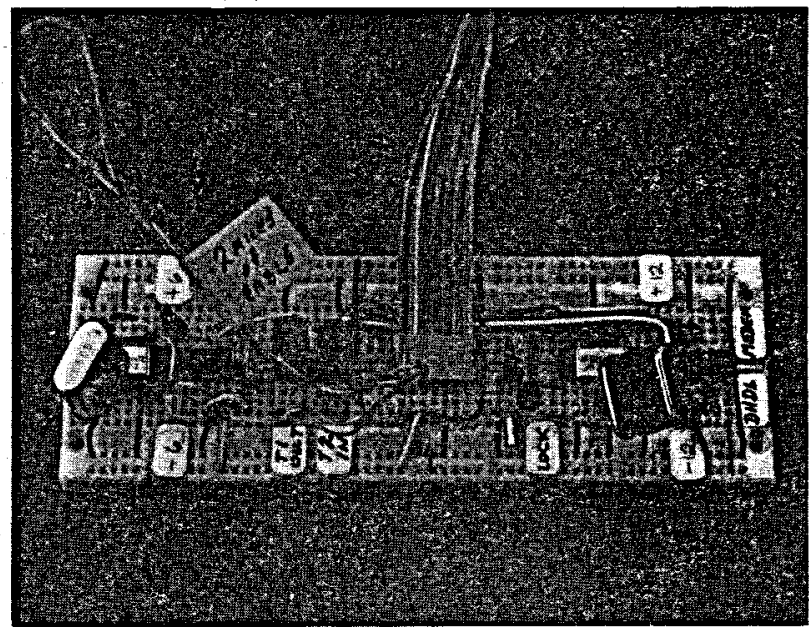

Fig. 20. Optional modem.

for Mapping Vertical Conductive Fractures: Status Report," Los Alamos Scientific Laboratory report LA-7049-SR, December 1977.

3. J. H. Moran and K. S. Kuntz, "Basic Theory of Induction Logging," Geophysics, December 1962.

4. H. B. Watt, G. W. Hammack, H. Guyod, P. A. Wichmann, L. E. Schneider, R. D. Wood, and D. W. Hilchie, Log Review 1 (Dresser Industries, Inc., Dallas, Texas, 1974).

5. J. A. Landt, "A Magnetic Induction Technique for Mapping Vertical Conductive Fractures: Theory of Operation," Los Alamos Scientific Laboratory report LA-7333-MS, July 1978.

6. R. W. Higgens, "Hydraulic System Design Aspects and Recommendations for an Induction Logging Too1," EG\&G 1183-5078, EG\&G, Inc., Los Alamos, New Mexico, April 1977. 
Printed in the United State's of America. Avaltable fron

Nutional Technical Information Service

L'S Depitriment of Commerie

5285 Port Royal Roud

Springfield, VA 2216

Microfiche $\$ 3.00$

$\begin{array}{llllllllll}001-025 & 4.00 & 126-150 & 7.25 & 251-275 & 10.75 & 376-400 & 13.00 & 501-525 & 15.25\end{array}$

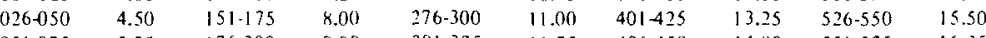

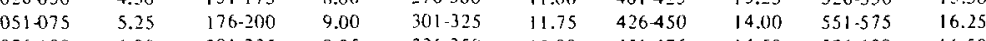

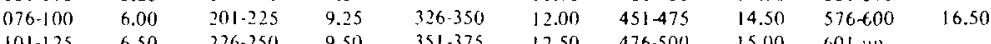

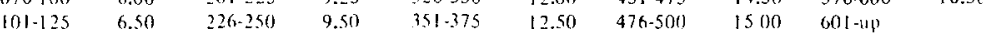

Nole: Add $\$ 2.50$ for each dedditional ton-page increment from 601 page up 